\title{
DESIGN OF WOOD CHIPS AND ASSOCIATED VOCS TREATMENT EQUIPMENT FOR WOOD PROCESSING
}

\author{
$\mathrm{Xu}$ Bo \\ School of Mechatronic Engineering \\ Southwest Petroleum University \\ Chengdu, Sichuan, China
}

\begin{abstract}
Wood chips and associated volatile organic compounds (VOCs) generated during wood processing need to be separated and treated before they can be discharged into the atmosphere. However, the pressure drop of existing equipment such as bag-type dust remover is large, short service life, large energy consumption and high maintenance cost, a set of wood chips and accompanying VOCs processing equipment is designed. The device consists of sieve tower, multi-tube guide vane cyclone and VOCs waste gas treatment equipment arranged in series. The dust-containing air flows through the primary screen and then passes through the dust removal of multi-tube guide vane cyclone into the VOCs waste gas treatment equipment to complete the waste gas treatment of wood processing. Based on the combination of theoretical calculation and field investigation, the structural design of a large number of components and the selection of VOCs waste gas treatment equipment were carried out, and the strength of key components was also checked and analyzed. It can provide reference for the design and development of dust removal and gas cleaning technology equipment in wood processing industry.
\end{abstract}

Keywords-Sawdust treatment; VOCs treatment; Multitube cyclone

\section{INTRODUCTION}

The pollution of wood industry dust particles and VOCs (Volatile Organic Compounds), volatile organic compounds, is particularly prominent in air pollution ${ }^{[1]}$, especially in the process of machine tool processing, producing fine wood strips, thin wood chips, shavings, wood flour, etc. At the same time, various types of wood chips of various sizes can be used in the production of wood products, such as paints, organic solvents, which generate a large amount of volatile organic compounds. Improper handling can cause serious air pollution and cause great harm to human health ${ }^{[2]}$. Therefore, how to solve the problems of large difference in the size of wood chip waste and a large number of volatile organic compounds in the processing of wood processing waste gas has become a key

\author{
Han CJ \\ School of Mechatronic Engineering \\ Southwest Petroleum University \\ Chengdu, Sichuan, China
}

link in the sustainable development of wood processing ${ }^{[3]}$. To this end, the design of a device capable of efficiently separating and dissolving all kinds of wood chips while purifying the exhaust gas of VOCs is of great significance to the green development of the wood processing industry.

At present, there are two methods commonly used for the treatment of wood chips ${ }^{[4]}$ : one is cyclone dust collector, which uses a dust-containing gas stream to change the direction of the fluid, so that the solid particles in the gas stream are separated by centrifugal force and gravity. Although the method is compact and low in cost, it generally has a dust removing effect on wood chips having a particle diameter of $10 \mu \mathrm{m}$ or more, and dust removal efficiency of dust particles of $10 \mu \mathrm{m}$ or less, particularly $5 \mu \mathrm{m}$ or less is low, and has almost no effect. Another method is to use a bag filter. The bag is made of textile filter cloth or felt cloth, uses the size of the mesh of the bag to filter the wood chips, which has high efficiency and simple structure, but the filter type dust removal mechanism leads to the modification mode. The working pressure drop is large and the energy consumption is high. The wind speed can not be very high for the treatment of high concentration dusty gas, and the bag has a short service life and high maintenance cost. It is necessary to design a more convenient and quick cleaning device to improve the working efficiency of the equipment, less maintenance cost and save maintenance time ${ }^{[5]}$.In the application of VOCs waste gas treatment, there are mainly activated carbon adsorption technology, condensation recovery technology, thermal incineration technology, photo catalytic degradation technology ${ }^{[6]}$.In summary, the author designed a set of highefficiency and energy-saving wood chip separation equipment integrated with exhaust gas treatment for wood processing wood chips and associated VOCs processing equipment.

\section{STRUCTURAL DESIGN AND WORKING PRINCIPLE}

\subsection{Structural composition and connection}

Figure 2 shows the overall structure of the wood chips and associated VOCs treatment equipment. It consists of three parts: the screen tower, the multi-tube vane cyclone and the VOCs exhaust gas treatment equipment. 


\section{International Journal of Engineering Applied Sciences and Technology, 2019 Vol. 4, Issue 7, ISSN No. 2455-2143, Pages 58-64 \\ Published Online November 2019 in IJEAST (http://www.ijeast.com)}

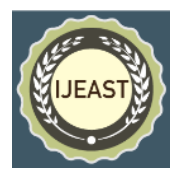

The front end of the screen tower is connected to the wood production and processing workshop, which is the inlet of the dusty airflow, and the rear end is connected with a multi-tube vane type cyclone dust collector. The upper tower of the screen tower is installed with a three-sided v-shaped hole screen to carry out the dusty airflow. The primary screen is used to separate the large-sized sawdust waste; the lower tower is the ash bucket, which is used to store the sawdust waste that is screened by the sieve.

Multi-tube vane type cyclone dust collector for separating small-sized wood chips and dust in dusty airflow. It consists of 21 single-tube cyclones ${ }^{[7]}$ connected in parallel. It is divided into three parts: the inlet chamber, the dust collection chamber and the gas collection chamber through two partitions welded with the main tube and the riser tube of the single tube. The inlet chamber and the front end screen The net tower is connected, and the ash hopper is arranged at the lower end of the dust collecting chamber, and the upper end of the plenum is connected to the VOCs processing equipment through the external pipeline. The single-tube cyclone is the main separation component of the dust collector. It consists of four parts: the main cylinder, the guide vane, the riser pipe and the guide cone. The main cylinder is connected to the inlet chamber, and the guide vane has the guidance and acceleration of the air flow. The upper and lower ends of the riser pipe are respectively connected with the gas collecting chamber and the dust collecting chamber, and the guiding cone is installed in the lower end of the main cylinder in the dust collecting chamber.

The VOCs exhaust gas treatment equipment is installed at the tail end of the whole device for treating volatile organic compounds in the gas after dust removal. The flow plate is placed at the gas inlet to make the gas flow evenly after entering the equipment, which is beneficial to improve gas treatment efficiency; The ultraviolet lamp tube group emits a special band of ultraviolet rays to degrade the volatile organic compounds in the gas; a gas component safety monitoring system is installed at the gas outlet end passage, and the gas that meets the discharge standard is directly discharged into the atmosphere.

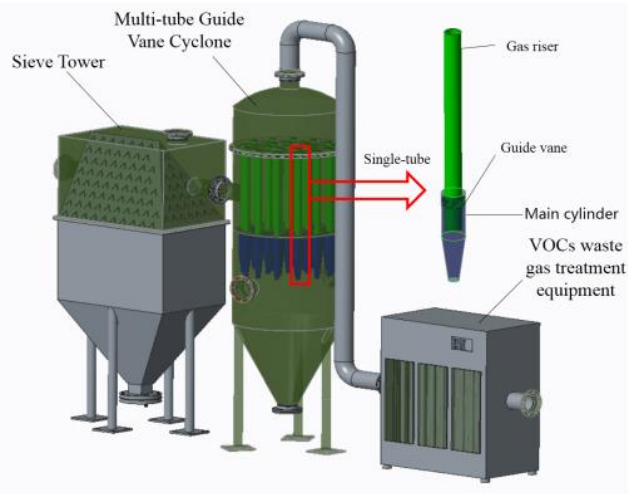

Fig. 1.Overall structure model of wood chips and associated VOCs processing equipment

\subsection{Working principle}

After the dust flow of wood processing is discharged, the airflow enters the screen tower. The larger particle size cannot pass through the three-sided V-shaped screen, and falls into the lower tower of the screen tower under the action of gravity potential energy. The gas is sieved and the sieve is sieved. The gas enters the inlet chamber of the multi-tube vane cyclone from the side inlet, gathers and squeezes in the inlet chamber and flows into each single-tube cyclone, and the airflow moves linearly downward along the axis under the action of the guide vanes. It is converted into tangential motion, and then the wood chips in the airflow are smashed to the wall surface by the density difference of the gas-solid two phases, and the falling cone wall is dropped to the dust collecting chamber, and the purified gas reaches the bottom of the main cylinder and enters the guiding cone to form a reversal. Swirl upward, and the gas pipe enters the gas collection chamber. At this time, the solid phase particles in the gas are extremely low, and the wood chips in the exhaust gas are processed. Furthermore, the gas enters the VOCs processing equipment, and the gas is smoothly and uniformly reacted with the ultraviolet rays of the special band emitted by the UV ultraviolet lamp tube under the action of the current equalizing plate, so that the volatile organic substances in the exhaust gas are sufficiently degraded. Finally, the gas component safety monitoring system at the exit end of the equipment monitors the composition index of the external exhaust body in real time, and completes the processing of wood chips and associated VOCs in wood processing.

\section{DESIGN OF EACH COMPONENT}

\subsection{Working condition analysis}

Through on-the-spot investigation of the wood processing plant, the treatment air volume of the factory exhaust gas treatment device reaches $60,000 \mathrm{~m} 3 / \mathrm{h}-80000 \mathrm{~m} 3 / \mathrm{h}$. The main solid phase composition in the gas stream to be treated is shown in Table 1 , and the VOCs content in the gas stream is $\leqslant$ $200 \mathrm{mg} / \mathrm{M} 3$, the overall operating pressure is $\leqslant 1.32 \mathrm{MPa}$, so the processing device housing made of general $10 \mathrm{~mm}$ steel plate can meet the strength requirement.

Table -1 Statistics of airflow composition to be treated

\begin{tabular}{|c|c|c|c|}
\hline $\begin{array}{c}\text { Main } \\
\text { composition }\end{array}$ & Particle size & content & Approach \\
\hline $\begin{array}{c}\text { Wood shavings, } \\
\text { etc. }\end{array}$ & $\begin{array}{c}1000 \mu \mathrm{m} \text { or } \\
\text { more }\end{array}$ & $60 \%$ & $\begin{array}{c}\text { Screen, multi-tube } \\
\text { cyclone }\end{array}$ \\
\hline Sawdust & $\begin{array}{c}100 \mu \mathrm{m}- \\
1000 \mu \mathrm{m}\end{array}$ & $30 \%$ & \begin{tabular}{c} 
Multi-tube cyclone \\
\hline Dust
\end{tabular} \\
\hline
\end{tabular}

\subsection{Design of large particle size treatment equipment}

According to the above-mentioned on-the-spot investigation of wood processing factories, large-scale particle shavings and the like are occupied, and the processing volume is huge. In order to ensure the working efficiency of subsequent 


\section{International Journal of Engineering Applied Sciences and Technology, 2019 Vol. 4, Issue 7, ISSN No. 2455-2143, Pages 58-64 \\ Published Online November 2019 in IJEAST (http://www.ijeast.com)}

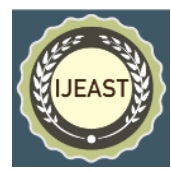

processing devices such as small-size wood chips, solid-phase shavings, wood chips, etc. The superposition and separation are designed according to the particle size, and the sieve tower is designed at the entrance to screen the large-size shavings. The overall structure is shown in Figure 2.

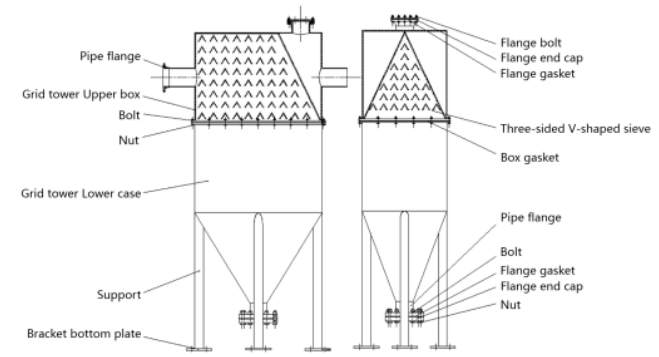

Fig. 2.Overall structure of the sieve tower

\subsubsection{Screen design}

By designing a three-sided $\mathrm{V}$-shaped screen to increase the gas flow area to meet the processing air volume requirements, as shown in Figure 3 (a), the overall size of the screen is length $\times$ width $\times$ height: $1500 \mathrm{~mm} \times 1000 \mathrm{~mm} \times 800 \mathrm{~mm}$. The common steel wire mesh is easy to block, easy to deform, and has a short life. It is connected to the tower body by means of the bottom of the $3 \mathrm{~mm}$ steel plate material. The screen is used for the separation of light and large shavings and wood chips. Combined with the actual situation of the wood processing factory, wood chips above $10 \mathrm{~mm}$ will reduce the dust removal efficiency of the subsequent dust removal device. Therefore, the mesh hole is designed to be $60^{\circ} \mathrm{V}$ to increase the flow area. As shown in Fig. 3(b), the hole diameter is $10 \mathrm{~mm}$ and the span is $120 \mathrm{~mm}$. It is machined by milling. The screen structure is simple and easy to process. In order to ensure the pressure drop of the large air volume processing conditions and reduce the risk of clogging, the $\mathrm{V}$-shaped mesh holes should be distributed on as many as three sides of the screen.

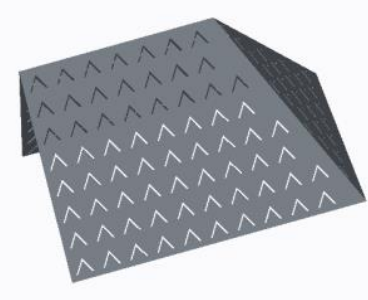

(a)

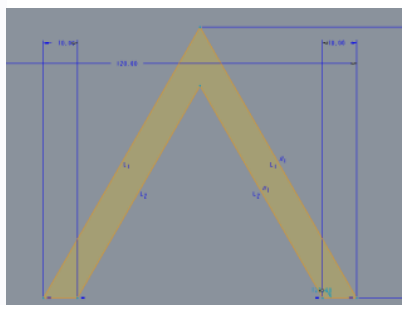

(b)
Fig. 3. Schematic diagram of the size structure of the screen

\subsubsection{Sieve tower design}

The screen tower is divided into upper and lower towers as shown in Fig. 3. The screen is installed in the upper tower body, and the airflow is screened through the upper tower body. The internal dimensions are matched with the size of the screen. The design of the pressure vessel is calculated to have a wall thickness of $10 \mathrm{~mm}$. It not only saves material space, but also meets the needs of pressure intensity. For the intake and exhaust pipes, a standard pipe with a diameter of $200 \mathrm{~mm}$ and a wall thickness of $6 \mathrm{~mm}$ can be used to meet the requirements of handling air volume and strength. An operating hole ${ }^{[8]}$ is opened above the tower body to facilitate inspection of the inside of the device and to deal with problems such as blockage of wood shavings.

The lower tower body is mainly used to support the upper tower body and store the separated wood chips and shavings. It is connected with the upper box by bolts, and the bottom opening and unloading port. The internal space is determined according to the length of the unloading cycle.

\subsection{Design of multi-tube vane type cyclone dust collector 2.3.1 Design of cyclone guide vanes}

The single-tube cyclone is an important component of the multi-tube vane-type cyclone dust collector. The parameters of the guide vane have a direct influence on the separation efficiency. For the separation of sawdust dust, multi-tube arrangement is adopted, the intake air is relatively uniform, and the separation is thorough, the bottom of the cyclone. The use of the guiding cone structure can greatly reduce the occurrence of cross-flow back mixing. The curved blade structure is reasonable, the risk of being blocked is small [9], and the processing and manufacturing are convenient. The common specifications of the cyclone ${ }^{[10]}$ are $\phi 100 \mathrm{~mm} 、 \phi 150 \mathrm{~mm}$ 、 $\phi$ three kinds of $250 \mathrm{~mm}$. Choose here $\phi 108 / 76 \mathrm{~mm}$ cyclone, the outer tube diameter is $108 \mathrm{~mm} r 2=54 \mathrm{~mm}$, the inner tube diameter is $76 \mathrm{~mm} r 1=38 \mathrm{~mm}$, the inlet angle $\alpha$ is $90^{\circ}$, the exit angle $\beta$ is $30^{\circ}$, the number of blades $n$ is 8 , the thickness of the blade $\delta$ take $4.5 \mathrm{~mm}$, the two adjacent blade coincidence degree $\gamma$ takes 33\%, as shown in Figure 4.

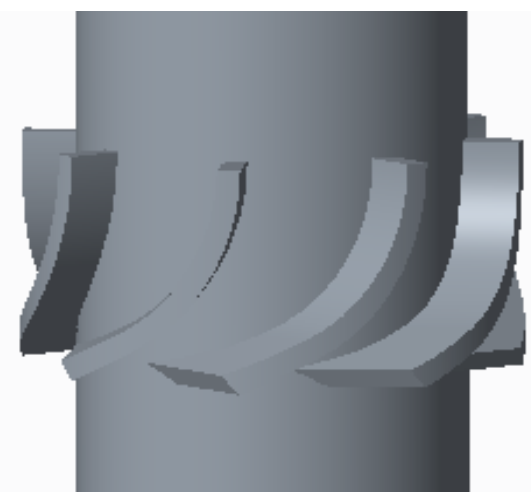

Fig. 4. Schematic diagram of the guide vane structure

Table -2 Main dimensions of the guide vanes

\begin{tabular}{|c|c|c|c|c|c|c|}
\hline Name & $\begin{array}{c}\text { Number } \\
\text { of } \\
\text { blades } \\
\text { (a) }\end{array}$ & $\begin{array}{c}\text { Blade } \\
\text { thickness } \\
(\mathbf{m m})\end{array}$ & $\begin{array}{c}\text { Distance } \\
\text { between } \\
\text { blade } \\
\text { and inlet } \\
\text { section } \\
\text { (mm) }\end{array}$ & $\begin{array}{c}\text { Blade } \\
\text { exit } \\
\text { angle } \\
(\mathbf{m m})\end{array}$ & $\begin{array}{c}\text { Blade } \\
\text { package } \\
\text { arc } \\
\text { length } \\
\text { (mm) }\end{array}$ & $\begin{array}{c}\text { Blade } \\
\text { height } \\
\text { (mm) }\end{array}$ \\
\hline Symbol & $\mathrm{n}$ & $\mathrm{s}$ & $\mathrm{f}$ & $\beta$ & $\mathrm{L}$ & $\mathrm{h}$ \\
\hline Size & 8 & 4.5 & 25 & 30 & 45 & 47 \\
\hline
\end{tabular}




\section{International Journal of Engineering Applied Sciences and Technology, 2019 Vol. 4, Issue 7, ISSN No. 2455-2143, Pages 58-64 \\ Published Online November 2019 in IJEAST (http://www.ijeast.com)}

\subsubsection{Design of inner and outer tube structure of cyclone}

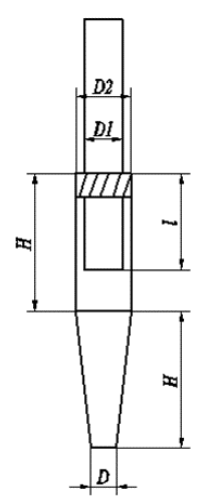

Fig. 5. Cyclone main size chart

(1) Determination of the length of the outer tube cylinder section:

The long inner tube insertion depth can improve the dust removal efficiency of the cyclone, but the excessively long outer tube will increase the pressure drop of the precipitator, so the length to diameter ratio of the outer tube is generally selected:

$$
\hat{\mathrm{H}}=\mathrm{H} / \mathrm{D}_{2}=2.5
$$

Substituting $\mathrm{D}_{2}=108 \mathrm{~mm}$ into equation (2.1): outer tube cylinder length $\mathrm{H}=270 \mathrm{~mm}$. The length of the cone section is similar to the length of the cylinder section, and the length of the cone section is taken. $\mathrm{H}_{2}=270 \mathrm{~mm}$.

(2) Determination of the insertion depth of the inner tube:

The ratio of the depth of the inserted person to the length of the outer tube barrel:

$$
1 / \mathrm{H}=0.7
$$

Substituting $\mathrm{h}=270 \mathrm{~mm}$ into equation (2.2): inner tube insertion depth $1=189 \mathrm{~mm}$.

(3) Determination of the diameter of the ash outlet at the bottom of the cone:

The diameter of the ash outlet at the bottom of the long cone is similar to the diameter of the inner tube. If it is too small, cross-flow back mixing ${ }^{[11-12]}$ may occur. If it is too small, the internal swirl will be unstable, which will affect the internal rotation of the airflow ${ }^{[13]}$. The diameter of the ash outlet at the bottom of the cone $=50 \mathrm{~mm}$.

In summary, the main dimensions of the inner and outer tube structures of the cyclone are shown in Table 3.

Table -3 Main dimensions of the inner and outer tube structures of the cyclone

\begin{tabular}{|l|l|l|l|l|} 
Name & Outer & Outer cone & Inner tube & The diameter
\end{tabular}

\begin{tabular}{|c|c|c|c|c|}
\hline & $\begin{array}{c}\text { cylinder } \\
\text { length }(\mathbf{m m})\end{array}$ & $\begin{array}{c}\text { length } \\
\mathbf{m m})\end{array}$ & $\begin{array}{c}\text { insertion } \\
\text { depth }(\mathbf{m m})\end{array}$ & $\begin{array}{c}\text { of the ash } \\
\text { outlet at } \\
\text { the bottom of } \\
\text { the cone }(\mathbf{m m})\end{array}$ \\
\hline Symbol & $\mathrm{H}$ & $\mathrm{H}_{2}$ & 1 & $\mathrm{D}$ \\
\hline Size & 270 & 270 & 189 & 50 \\
\hline
\end{tabular}

\subsubsection{Design of other parameters of multi-tube vane type cyclone dust collector}

(1) Determination of the diameter of the precipitator:

The spacing of adjacent cyclones cannot be too small, and the inconvenience of installation will not affect the flow field state at the ash discharge port, so the center distance is generally 1.4-1.5 times the diameter of the outer diameter of the cyclone. $\mathrm{D}_{2}$. The distance between the outermost cyclone center and the dust collector wall is desirable $\mathrm{D}_{2}$. The cyclone can be arranged in a concentric circle ${ }^{[7]}$. Here, in the case of a cyclone in the center, the diameter of the precipitator:

$$
D=(3 n+2) D_{2}
$$

Where $\mathrm{n}$ is the number of turns of the cyclone, substituting $\mathrm{n}=3, \mathrm{D}_{2}=108 \mathrm{~mm}$ into equation (2.3): dust collector diameter $\mathrm{D}=1180 \mathrm{~mm}$.

From the size of $\mathrm{D}$, the number of cyclones $\mathrm{n}$ is preferably 21. The specific arrangement is shown in the figure below.

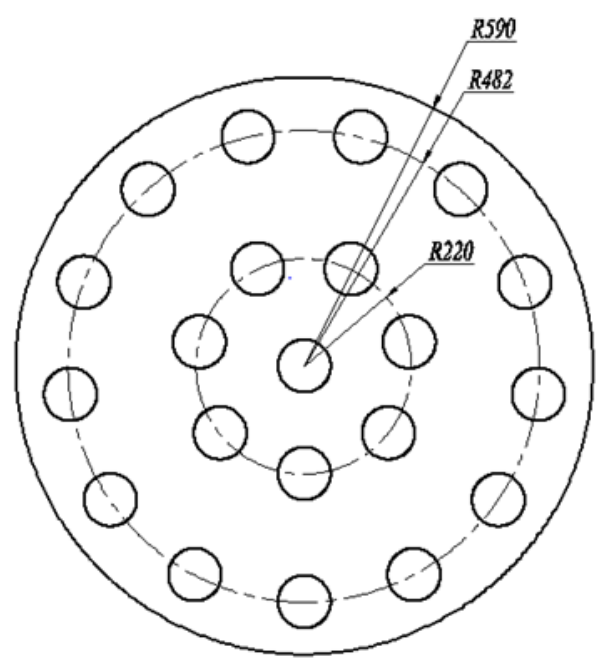

Fig. 6. Layout of the cyclone in the lower partition

(2) Determination of operating pressure:

$$
\mathrm{Q}=1.1 \times 10^{6} \mathrm{NF}_{\mathrm{i}} \mathrm{p}
$$

In this formula:

Q- Multi-tube cyclone treatment capacity, $\mathrm{Nm}^{3} /$ day.

$\mathrm{F}_{\mathrm{i}-}$ The axial air intake area of a single cyclone, $\mathrm{m}^{2}$. 


\section{International Journal of Engineering Applied Sciences and Technology, 2019 Vol. 4, Issue 7, ISSN No. 2455-2143, Pages 58-64 \\ Published Online November 2019 in IJEAST (http://www.ijeast.com)}

p- The operating pressure of the multi-cyclone dust collector, $\mathrm{kg} / \mathrm{cm}^{2}$.

Axial air intake area of a single cyclone:

$$
\mathrm{F}_{\mathrm{i}}=\pi\left(\mathrm{r}_{2}^{2}-\mathrm{r}_{1}^{2}\right)
$$

In this formula:

$r_{2}$ - the outer diameter of the cyclone outer tube, $\mathrm{m}$.

$\mathrm{r}_{1}$ - the radius of the inner diameter of the cyclone, $\mathrm{m}$.

Substituting q=60000 $\times 24 \mathrm{Nm}^{3} /$ day, $\mathrm{N}=21$, formula $(2.5)$ into equation (2.4): operating pressure of multi-tube cyclonep $\approx 13.49 \mathrm{~kg} / \mathrm{cm} 2=1.32 \mathrm{Mpa}$.

(3) Determination of the axial flow velocity of the cyclone:

$$
\mathrm{C}_{\mathrm{i}}=\mathrm{TQ} /\left(2.4 \times 10^{6} \mathrm{NF}_{\mathrm{i}} \mathrm{p}\right)
$$

In this formula, T- working temperature, take $40^{\circ} \mathrm{C}$.

Substituting $\mathrm{q}=60000 \times 24 \mathrm{Nm}^{3} /$ day, $\mathrm{N}=21$, Equation (2.6) into equation (2.4): Cyclone axial airflow velocity $\mathrm{C}_{\mathrm{i}} \approx$ $18.3 \mathrm{~m} / \mathrm{s}$.

(4) Determination of the pressure drop of the precipitator:

$$
\square \mathrm{p}=\xi_{\mathrm{g}} \mathrm{C}_{\mathrm{i}}^{2} / 2 \mathrm{~g}
$$

In this formula:

$\xi$ - Cyclone drag coefficient, 12.7.

$\mathrm{r}_{\mathrm{g}}$ - the severity of the treatment gas, $\mathrm{kg} / \mathrm{m}^{3}$.

g- Gravity acceleration, $9.8 \mathrm{~m} / \mathrm{s}^{2}$.

Substituting $\xi=12.7, \quad r_{g}=2 \times 10-3 \mathrm{~kg} / \mathrm{m}^{3}, \mathrm{~g}=9.8 \mathrm{~m} / \mathrm{s}^{2}$ into equation (2.7): Dust collector pressure drop $\Delta \mathrm{p} \approx 0.43$ $\mathrm{kg} / \mathrm{m}^{2}=0.042 \mathrm{Mpa}$.

In summary, the design of the remaining parameters of the multi-tube vane cyclone is shown in Table 4.

Table -4 Design of the remaining parameters of multi-tube vane type cyclone

\begin{tabular}{|c|c|c|c|c|c|}
\hline Name & $\begin{array}{c}\text { Dust } \\
\text { collector } \\
\text { diameter } \\
(\mathbf{m m})\end{array}$ & $\begin{array}{c}\text { Cyclone } \\
\text { number } \\
(\mathbf{a})\end{array}$ & $\begin{array}{c}\text { Operating } \\
\text { pressure } \\
(\mathbf{M P a})\end{array}$ & $\begin{array}{c}\text { Axial air } \\
\text { flow rate } \\
(\mathbf{m} / \mathbf{s})\end{array}$ & $\begin{array}{c}\text { Pressure } \\
\text { drop } \\
(\mathbf{M P a})\end{array}$ \\
\hline Symbol & $\mathrm{D}$ & $\mathrm{N}$ & $\mathrm{p}$ & $\mathrm{C}_{\mathrm{i}}$ & $\Delta \mathrm{p}$ \\
\hline Size & 1180 & 21 & 1.32 & 18.3 & 0.042 \\
\hline
\end{tabular}

\subsubsection{Design of multi-tube vane type cyclone dust} collector

Main design parameters:

(1) Upper cylinder size: length $1200 \mathrm{~mm}$, height $820 \mathrm{~mm}$, width $1200 \mathrm{~mm}$

(2) Lower cylinder size: length $1200 \mathrm{~mm}$, height $820 \mathrm{~mm}$, width $3500 \mathrm{~mm}$
As shown in Fig. 7, the cylinder is mainly used for discharging the gas treated by the dust collector. As shown in Fig. 8, the cylinder is mainly used for supporting the dust collector and storing the separated wood chips and dust. Calculated by the above formula, the operating pressure is $1.32 \mathrm{MPa}$, which can meet the strength requirement by using the commonly used $10 \mathrm{~mm}$ steel plate. The upper and lower cylinders are bolted. In addition, the upper partition of the precipitator should be installed in the bottom of the upper cylinder in the form of welding; there are two operating holes on both sides of the cylinder for checking the working condition of the cyclone inside the separator to facilitate the daily maintenance of the cyclone.

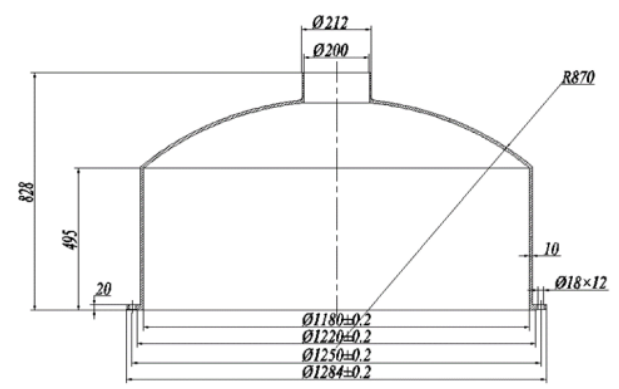

Fig. 7. Multi-tube dust collector upper cylinder

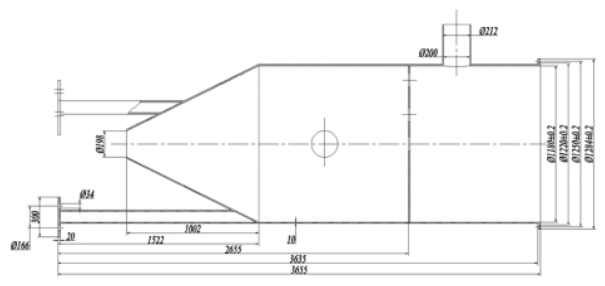

Fig. 8. Multi-tube dust collector lower cylinder

\subsection{Selection of VOCs waste gas treatment equipment}

In view of the fact that the research and production of photo catalytic catalytic processing equipment ${ }^{[14]}$ on the market has been relatively perfect, many manufacturers in the country can manufacture and manufacture. Therefore, the equipment used in the processing of wood is selected from Botou City Xianglu Environmental Protection. The JHRRCO6000 Photo Oxygen Catalytic Equipment manufactured by Equipment Co., Ltd. is used to process VOCs exhaust gas. The specific parameters are as follows. In addition, a gas composition safety monitoring system can be installed at the gas outlet end.

\begin{tabular}{|c|c|}
\hline Product indicators & Parameter \\
\hline Product number & JHRRCO-6000 \\
\hline Dimensions (mm) & $3600 \times 1650 \times 2100$ \\
\hline $\begin{array}{c}\text { Handling air volume } \\
(\mathrm{m} 3 / \mathrm{h})\end{array}$ & 60000 \\
\hline $\begin{array}{c}\text { Treatment of exhaust gas } \\
\text { concentration }(\mathrm{mg} / \mathrm{m} 3)\end{array}$ & $\leqslant 400$ \\
\hline
\end{tabular}




\section{International Journal of Engineering Applied Sciences and Technology, 2019 \\ Vol. 4, Issue 7, ISSN No. 2455-2143, Pages 58-64 \\ Published Online November 2019 in IJEAST (http://www.ijeast.com)}

\begin{tabular}{|c|c|}
\hline Processable exhaust type & $\begin{array}{c}\text { Hydrogen sulfide, lipids, } \\
\text { alcohols, aldehydes, benzenes, } \\
\text { alkanes, etc. }\end{array}$ \\
\hline Installation method & Flange connection \\
\hline
\end{tabular}

\subsection{Part strength check analysis}

\subsubsection{Pipe compression strength check}

The gas transportation of the whole device adopts the pipeline shown in Fig. 9. The outer diameter is $\mathrm{D}=212 \mathrm{~mm}$, the wall thickness is $t=6 \mathrm{~mm}$, the material is alloy steel, the tensile strength is $980 \mathrm{MPa}$, and the shear strength is $490 \mathrm{Mpa}$.

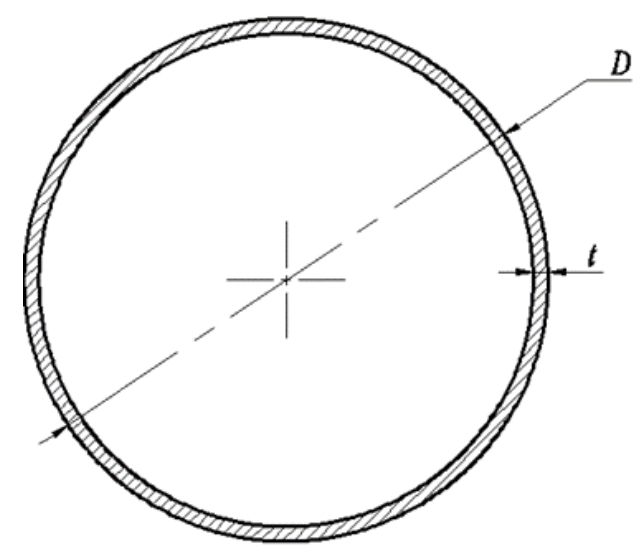

Fig. 9. Schematic diagram of pipe size

\subsubsection{Analysis of tensile strength of cyclone inner tube}

The uppermost end of the single-tube cyclone inner tube was set as a fixed constraint, and the operating pressure on the blade was 1.3 MPa. Figure 10 shows the Von-Mises stress cloud diagram of the cyclone inner tube. Under this pressure, the stress is about $10 \mathrm{MPa}$, which is much smaller than the yield stress of $620 \mathrm{MPa}$. Figure 11 is its displacement cloud diagram, its deformation is very small, the maximum displacement is $0.00003 \mathrm{~mm}$ negligible, it can be concluded that the strength and performance of the single-tube cyclone guide vane and the riser meet the design requirements.
Fig. 10. Stress cloud diagram of cyclone inner tube

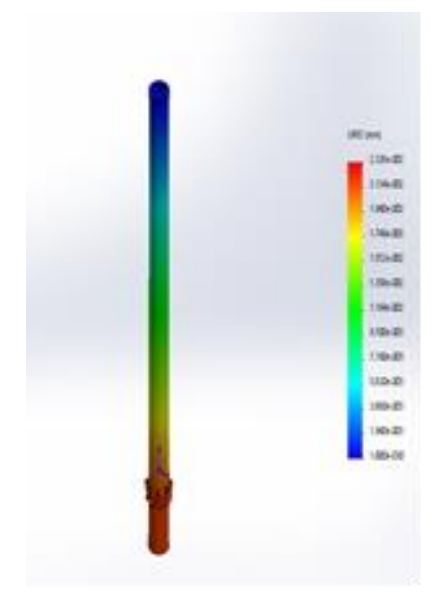

Fig. 11. Displacement cloud diagram of cyclone

\subsubsection{Strength analysis of the upper cylinder of the cyclone separator}

The lower edge of the upper body of the cyclone separator is set as a fixed constraint, and the operating pressure on the inner wall is $1.3 \mathrm{MPa}$. Figure 12 shows the Von-Mises stress cloud diagram of the upper cylinder. Under this pressure, the stress is about $200 \mathrm{MPa}$, which is close to the yield stress of $282 \mathrm{MPa}$. There is stress concentration at the junction between the circular arc surface and the straight section. Therefore, it should be chamfered here. Figure 13 is a displacement cloud diagram with a small amount of deformation and a maximum displacement of $0.69 \mathrm{~mm}$ within the allowable range of strength.

In summary, the strength and performance of the upper cylinder meet the design requirements, and the sharp corners of the detail should be chamfered to prevent stress concentration.
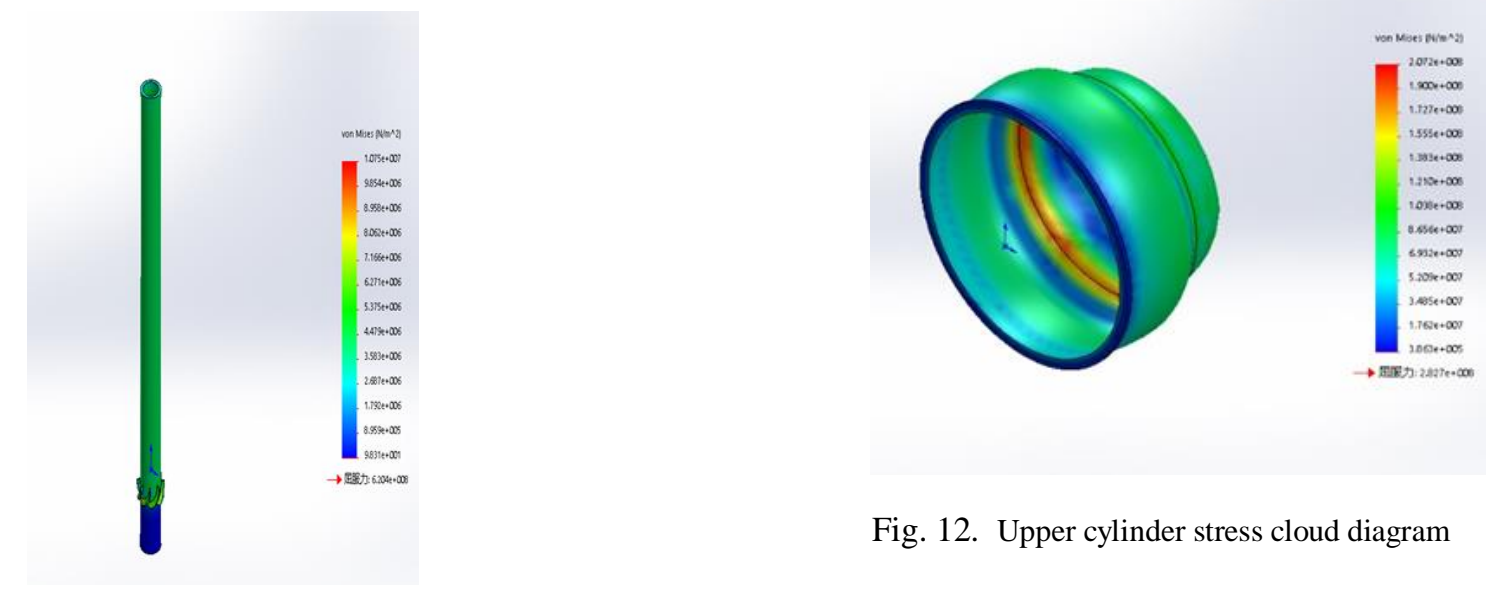

Fig. 12. Upper cylinder stress cloud diagram 


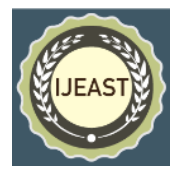

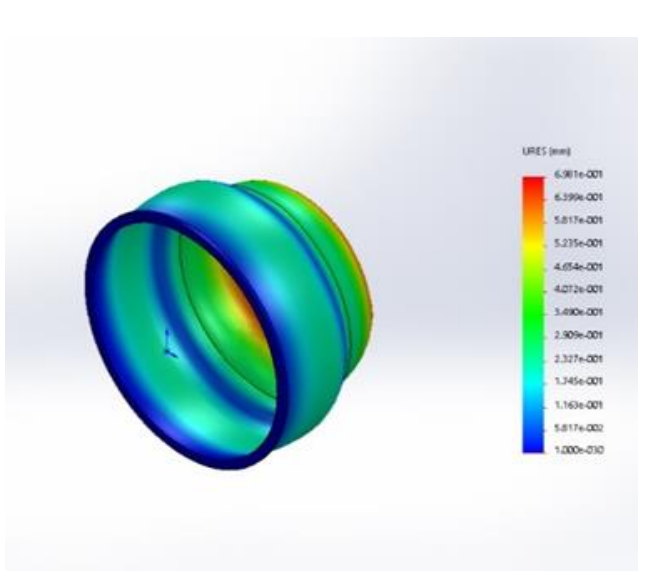

Fig. 13. Upper cylinder displacement cloud diagram

\section{CONCLUSION}

Starting from the practical problems of waste gas treatment in wood processing plants, combined with theoretical calculations and research methods, the device adopts the method of superposition and separation according to the particle size of wood shavings and wood chips, which can more effectively separate solid phase impurities in exhaust gas, and creatively design three-sided v-type. The hole screen and the multi-tube vane type cyclone dust collector make the overall pressure drop of the device low, the structure is simple, the installation is convenient, the stability is good, the maintenance cost is reduced, the energy consumption is saved, and the device realizes the exhaust gas. One-stop treatment, the treated gas can be directly discharged into the atmosphere, providing reference for the design and development of dust removal and gas purification technology equipment in the wood processing industry.

\section{REFERENCE}

[1] XIONG Zhenhua,QIAN Feng,SU Rongrong.Research Progress on Distribution Characteristics and Sources of VOCs in Atmosphere[J].Environmental Science and Technology,2013,36(S2):222-228.

[2] Zhang Xiangfeng. Wood dust dust explosion prevention and control measures [j]. Labor Protection, 2017 (09): 2930 .

[3] Jing Xiao. Research on dust collector industry [d]. Southwestern University of Finance and Economics, 2014.

[4] Wang Xinhua. Experimental study on gas-solid two-phase flow control mechanism in guide vane cyclone [d]. China University of Petroleum, 2010.

[5] Zhang Liancheng. The principle of bag filter and dust removal in factory [j]. SME management and technology (late period) 2010 (06): 194.
[6] Zhai Zhiqiang, Hao Zhengping, Wang Xiqin. Analysis and Evaluation of VOCs Treatment Technology for Industrial Fixed Sources $[\mathrm{J}]$. Environmental sciences,2011,32(12):3476-3486.

[7] Yang Xue. Separation performance of multi-tube cyclone separator and optimization design of guide vane [d]. Southwest Petroleum University, 2016.

[8] Yuan Yi, Sun Guogang, Zhou Fazhen, Yang Xiaonan. Calculation of pressure drop of cyclone separator [j]. Oil Refining Technology and Engineering, 2016, 46(10): 3944.

[9] Han Chuanjun, Chen Fei, Yang Xue, Zhang Jie. Effect of blade parameters on the performance of vane-type cyclone separation tube[j]. Mechanical Design, 2015, 32(08): 72-77.

[10] Li Qi. Flow field simulation analysis of multi-tube dry separator [a]. Natural Gas Professional Committee of China Petroleum Institute, Sichuan Petroleum Institute. Proceedings of 2016 National Natural Gas Academic Annual Conference [c]. Natural Gas Professional Committee of China Petroleum Institute Sichuan Petroleum Institute: Natural Gas Professional Committee of China Petroleum Institute, 2016: 8.

[11] Gleb I Pisarev, Alex C Hoffmann. Effect of the 'end of the vortex' phenomenon on the particle motion and separation in a swirl tube separator[J]. Powder Technology, 2014(222): 101-107.

[12] Akira Ogawa. Estimations of the maximum tangential velocity $\mathrm{V} \theta \mathrm{m}$ in the vortex core region and also the mean rotational velocity Voi near the concave wall surface in the returned flow type cyclone dust collector $[\mathrm{J}]$. Journal of Thermal Science, 2010, 19(6):553-560.

[13] Li Qi, Luo Min, Han Chuanjun, Yang Xue, Guan Xiqi. Influence of taper on the flow field of cyclone separator for natural gas purification [j]. Oilfield Machinery, 2014, 43(12): 8-12.

[14] $\mathrm{Yu}$ Huizhen. Theoretical study on photocatalytic oxidation of VOCs by nano- $\mathrm{TiO}_{2}[\mathrm{~J}]$.Journal of Hefei University of Technology(Natural Science),2013,36(10):1249-1253. 